\title{
Systematic Review of Virtual Worlds applied in Education
}

\author{
Felipe Becker Nunes ${ }^{1}$, Fabrício Herpich ${ }^{1}$, Leo Natan Paschoal ${ }^{2}$, Liane Margarida \\ Rockenbach Tarouco ${ }^{1}$, José Valdeni de Lima ${ }^{1}$ \\ ${ }^{1}$ Universidade Federal do Rio Grande do Sul (UFRGS) \\ ${ }^{2}$ Universidade de Cruz Alta (UNICRUZ) \\ \{nunesfb, fabricio.herpich, leonatanpaschoal\}@gmail.com, \\ liane@penta.ufrgs.br, valdeni@inf.ufrgs.br
}

\begin{abstract}
Growth of research conducted over the past year involving the application of virtual worlds in the educational field enabled the development of didactic interventions, which aim to complement the learning process of students. Based on this assumption, this paper presents an analysis based on a systematic review of virtual worlds applied in the educational context seeking to highlight qualitative and quantitative information found during the application of a previously established protocol. Analysis of data provided enlightening information about certain listed aspects, taking as an example the allocated type of target audience, the areas of education and theories that have grounded the research conducted.
\end{abstract}

\section{Introduction}

Virtual worlds, also titled as immersive virtual environments or metaverse, are becoming very popular and consolidated in the academic area. Bell (2008) explains that virtual worlds are usually associated as 3D online environments that provide support for communication between multiple users simultaneously, and allows interaction with virtual objects in a persistently and synchronously form. Among the virtual worlds currently available, are Second Life, Open Wonderland and Open Simulator (OpenSim).

Graphical interface of these environments is visualized with use of a viewer, in which the user can interact and perform their activities, and there are several solutions as Singularity, Imprudence and Firestorm. User can interact with this environment through a character called avatar, which is your graphic and virtual representation, being possible customize its appearance according to the desired preferences.

As regards to the application of virtual worlds in the educational field, these three-dimensional spaces are representations of the real world, capable of promoting diverse user experiences, as passing a sensation of the student be immersed at the environment, stimulating different types of knowledge acquisition [Nunes et al. 2016]. Experiments developed in this type of environment results in low-cost technologies, which may represent classrooms, laboratories, simulators, games, allowing the user to have more involvement with the content that requires reflection by analyzing a visual representation for better understanding [Oliveira 2015].

Considering such characteristics of these environments, several studies have shown the use of virtual worlds in the educational field. In this respect, it is clear the 
V Congresso Brasileiro de Informática na Educação (CBIE 2016)

Anais do XXVII Simpósio Brasileiro de Informática na Educação (SBIE 2016)

need for a thorough analysis of these environments and their characteristics, which can be better organized when conducted through a systematic review of the subject.

With the objective of clarify what is being studied in the context of virtual worlds applied to education, in order to analyze the scientific production related to the theme and highlight possibilities for future research, this paper aims to present a systematic review of the literature. Thus, primary studies in article format were investigated, indexed by journals and national/international conferences, considering the period from 2010 to 2015. To achieve this, some research questions were developed, aiming to consolidate the quantitative and qualitative information founded.

\section{Related Work}

During this research, several studies that in some level are related to the theme of virtual worlds applied to education were analyzed, in order to observe the guidelines covered and note the methods employed by the authors. In the midst of this process, it is necessary to describe three works that are situated in the presented context.

In the research conducted by Borges et al. (2013), a systematic mapping on the prospects of gamification in the educational field was carried out. The process culminated in a final classification of 26 studies that were represented in a map, distributed among the types of studies and research goals.

Krassmann et al. (2014) presents a systematic mapping of assessments in the educational field for cloud computing deployments, considering investigations with assessments in the technological context, cost and benefit, satisfaction and didactics. Results allowed the classification of papers in the four contexts mentioned above, emphasizing the advantages that educational applications can get when performed in the cloud computing architecture.

The research conducted by Ghanbarzadeh et al. (2014) described the development of a systematic review of literature on different applications of virtual worlds in health, specifically in the context of medicine. Analysis of the authors obtained 62 papers from five scientific databases relevant to health and were classified in six categories: academic and professional education, treatment, evaluation, lifestyle and modeling. An increase number of inquiries on this subject was observed since 2006, being concentrated in the United States and United Kingdom.

Unlike the described papers, this study shows the design of a systematic review of literature aimed to identify and analyze the investigations conducted within virtual worlds applied to education in a more amplified form. Related studies showed the initiatives that aims to map the work in specific areas (health, cloud computing and gamification), showing methods and technologies aimed at educational level, which served as motivation for the development of this research, supported by the expanding use of these environments.

\section{Methodological Procedures}

From the point of view of its objectives, this study is composed of a systematic review of the literature. Kitchenham et al. (2007) defines it as a methodology to assess and interpret relevant primary researches to achieve secondary researches objectives. 
V Congresso Brasileiro de Informática na Educação (CBIE 2016)

Anais do XXVII Simpósio Brasileiro de Informática na Educação (SBIE 2016)

Therefore, this study was divided into four stages: review of the scope definition; search and selection of primary studies; data extraction; analysis and synthesis.

In the first stage, the period of the primary research socialized has been delimited, defined the languages of these research, seven research questions were developed, set the main bases of scientific data, constructed a string search and created a criteria for inclusion and exclusion. In this sense, the systematic review covers the period between 2010 and 2015, in which, was intended to disregard researches that may be outdated due to the emergence of technologies in recent years.

It is justified that was not considered papers published in 2016, since some databases had not disclosed the available work due to the period in which the review was carried out (first half of 2016). Table 1 presents the research questions established.

Table 1. Research questions created for this study

Q1: How are distributed and what are the developments of the investigations over the years?

Q2: What are the conferences and journals with the largest number of papers published?

Q3: What are the most researched topics in the context of Virtual Worlds in Education?

Q4: What were the educational theories applied with virtual worlds in the studies founded?

Q5: What are the viewers and platforms being used in the researches?

Q6: What forms of assessment of the study and the target audience (if any)?

Q7: What were the main results observed in the analyzed investigations?

To answer the questions, was considered only the texts in Portuguese and English language, from the databases presented in Table 2. It is noteworthy that the original names of events and journals were kept. Was selected some of the major national and international bases, which have in their majority ranking in quality indicators as the Qualis Capes, also, some of them have hold impact factor.

Table 2. Databases used in this study

- Congresso Internacional de Informática Educativa (TISE);

- Workshop de Informática na Escola (WIE);

- IEEE Transactions on Learning Technologies;

- Congresso da Sociedade Brasileira de Computação (Workshop sobre Educação em Computação);

- Journal of Virtual Worlds Research (JVWR);

- Revista Latino americana de Tecnologia Educativa (RELATEC);

- Simpósio Brasileiro de Informática na Educação (SBIE);

- Computers \& Education;

- Revista Novas Tecnologias na Educação (RENOTE);

- Creative Education;

- Informática na Educação: teoria \& prática;

- IEEE Computer Graphics and Applications;

- IEEE Revista Iberoamericana de Tecnologias del Aprendizaje.

To perform the examinations in the databases, a search string has been established based on the research questions. The term is composed of keywords considering its versions in Portuguese and English. It is emphasized that it was used in search engines that include automatic search. Thus, in some databases, such as TISE, which does not include the automatic search, was used the manual search method. 
V Congresso Brasileiro de Informática na Educação (CBIE 2016)

Anais do XXVII Simpósio Brasileiro de Informática na Educação (SBIE 2016)

The following string was used: ("mundos virtuais" OR "ambientes virtuais imersivos" OR "ambientes imersivos" OR metaversos OR "mundos digitais virtuais 3D" OR "ambientes virtuais multi usuários" OR "virtual worlds" OR "immersive virtual environments" OR "immersive environments" OR metaverses OR "digital virtual worlds 3D") AND (educação OR ensino OR aprendizagem OR education OR teaching OR learning). In this sequence, the "OR" operator is used to indicate that there are alternative terms and the operator "AND" is used to connect two terms.

To determine the inclusion of papers, considering some factors that helps identify the relevance of the primary studies to respond to the research questions, some inclusion and exclusion criteria were created. The criteria's has its origin in the related work [Borges et al. 2013; Ghanbarzadeh et al. 2014; Krassmann et al. 2014]. Thus, these criteria's are used as parameters to aid in the screening of publications.

The following inclusion criteria's (IC) were stipulated: Display virtual worlds applied to education in different fields of study and independent of platform (IC-1); Presents results that are consistent with the objective listed for the paper and with the instruments used in the evaluation of virtual worlds applied to education (IC-2). If it fit into one of these criteria, the paper was analyzed considering the exclusion criteria (EC), which, if it does not fit into any EC, it was approved, otherwise fail.

Exclusion criteria are: It does not address the application of virtual worlds in education (EC-1); Technical reports, documents that are available in the form of summary or presentations and also secondary literature reviews (EC-2); Addresses only theoretical and philosophical aspects (EC-3); Does not present results clearly and instruments used in the evaluation of virtual worlds applied to education (EC-4); Papers written in a language other than English or Portuguese (EC-5).

In the second stage of this research, search string of the application was carried out in the selected research sources. Subsequently, were found a total of 419 papers in the initial search. It is emphasized that the keywords can be anywhere in the paper.Third stage included the screening of the papers, in which were used the inclusion and exclusion criteria. Initially, in this step, the stage of selection was performed. This phase consists of reading the titles, abstracts and keywords of the 419 papers that were found in the previous stage. This process were conducted with the application of the inclusion and exclusion criteria, leaving the end of this phase with 113 papers included and 306 excluded. Is important clarifies that for each paper included, it had to fit in all the inclusion criteria, as for it to be deleted, it should fall into at least one exclusion criteria.

By the third stage, the 113 papers included in the screening participated in the extraction phase. At that stage, it was performed the complete reading of the publications selected in the previous step, that is, 113 papers were read and during the reading, criteria for inclusion and exclusion were applied. Finally, remained 58 included papers and 55 with exclusion. Papers included in this phase are available on the public address. The complete list of papers analyzed in this study is available in: https://docs.google.com/spreadsheets/d/1UeRFaXVaAREWEVZ9NpjYlyluBNk_jkKUZxjLrlOBWo/edit\#gid=1604517094

A complete new reading of publications drawn was held in the final stage, i.e., the 58 papers were read again considering the criteria of inclusion and exclusion, but 
V Congresso Brasileiro de Informática na Educação (CBIE 2016)

Anais do XXVII Simpósio Brasileiro de Informática na Educação (SBIE 2016)

this time, three researchers performed the reading. In the fourth stage of this research, papers were analyzed and categorized in order to answer the research questions and therefore for the objective of the study be reached. This step is detailed in the next section. Moreover, it is emphasized that three students with the supervision of two teacher's completed all stages of research.

\section{Analysis of the Results}

A visual representation was created in order to show the distribution of the papers per year and by the selected database. In Figure 1 it can be seen that the greater number of publications are concentrated in 2013, which represents $23 \%$ of all papers that have been discovered. The year with the lowest amount was in 2015, representing only $10 \%$ of the manuscripts, and $60 \%$ of them were socialized in Brazilian databases. It is observed that the number of publications has declined in recent years, and peaked between the years 2010 and 2013, possibly due to the expansion use of virtual worlds through Second Life and the emergence of new solutions for building free virtual worlds (e.g. OpenSim and Open Wonderland).

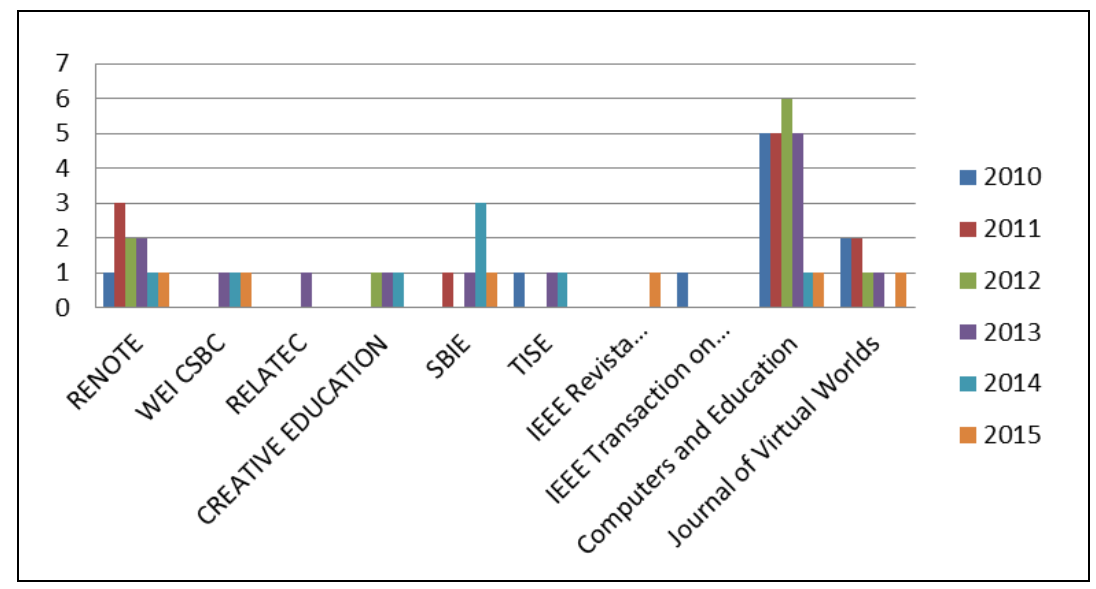

Figure 1. Distribution of publications per year and database

Figure shows that $40 \%$ of papers were published in the journal Computers and Education. This journal along with RENOTE, obtained publications in all the years considered in this systematic review, a feature that is not present in other existing options. SBIE was the only database that exceeded the number of Computers and Education publications, fact occurred in 2014. WEI maintained its number during the last three years, as for, the following databases did not have papers in 2015: RELATEC, Creative Education, TISE and IEEE Transaction on Learning Technologies.

Regarding to the types of virtual worlds that have been used over the past five years, analysis of results showed a scenario logically expected by the authors of this paper. This assertion is explained by the fact that Second Life was the most used (30 papers of 58), whereas among the options currently, such application can be considered the most established and widespread, both in academic, professional and personal.

Other virtual worlds were OpenSim (17), OpenWonderland (4) and a small group of solutions (6) were only used in one paper each. It is noteworthy that in one paper was not mentioned the type of virtual world used. Since OpenSim it's an application under development and emerged from the own Second Life, the lowest 
V Congresso Brasileiro de Informática na Educação (CBIE 2016)

Anais do XXVII Simpósio Brasileiro de Informática na Educação (SBIE 2016)

number is justified, noting that despite these indexes, it does not cease of be strongly competing with the SL.

As for the point of view related to time, the distribution presented by the analysis showed a predominance in the use of Second Life in the range of 2010 to 2013, as it is a period in which this application was highlighted in academic circles. After this, analysis shows that the number of applications began decrease due to the decreased use of this virtual world, and concomitant expansion of OpenSim, as well as Open Wonderland, taking space in the academic environment. Currently, it was possible to see a more balanced distribution between SL and OpenSim, with OpenWonderland and other smaller applications with a small amount of use.

In this context, as explained in section 1 of this paper, virtual worlds are viewed through an application called viewer. Results showed that 46 of the papers did not present explicitly the name of the viewer that was used. Within this scope, most papers used Second Life, which has an official viewer, being this considered as one of the reasons for not to be identified any mention of that application in these papers, as for is possible that the authors did not consider necessary to mention the type of viewer used.

As for the papers that cited the type of viewer used, which had the highest number of mentions was Firestorm (6), followed by Singularity (2), Imprudence (2) and Active Worlds Browser 3D (1). Also was cited in one paper Lumiya and Pixie Viewer for the visualization in mobile devices. These percentages show a predominance of Firestorm, which is an application that has several features required for manipulation of $3 \mathrm{D}$ objects in the virtual world, such as the ability to import files in XML and DAE format, creation of $3 \mathrm{D}$ objects, import multimedia files and supports scripting.

Regarding the different types of devices and resources that can be used in virtual worlds, using programming scripts in OpenSim Scripting Language (OSSL), native of the environment, it can be used in line with 3D objects, which the analysis performed showed that 54 papers from a total of 58 used such resources. Making an interconnection with the features present in this type of environment, the high use of 3D objects with scripts is justified because it is an interactive and immersive environment, in which, interactivity and authorship of users should be explored constantly.

Among other resources used, twelve papers also added multimedia materials such as videos, slides, texts and questions. This demonstrates the educational focus in this research conducted, as these types of resources was inserted as support to student's learning process. It becomes important to emphasize that although the number is not high compared to the total number of papers (56), it can be considered positive, since the inclusion of such resources involves more advanced knowledge in this type of environment, which increases the complexity of programming environment for users who are not used to.

It was also observed the use of Scratch on four papers, with the objective of assist in programming scripts for the $3 \mathrm{D}$ objects in the virtual world. The focus of use of this tool was on experiments involving programming with students, since it can be considered a valid alternative to assist in the learning process of this topic.

Non player characters (NPC), which are programmable entities through OSSL language to perform predefined actions, were used in five papers. Its goal from the 
educational point of view was centered on the fact of adding a higher level of interaction and conversation to these agents together with users, since it can be used as a tutor agent to instruct the student in carrying out educational activities in the virtual world. The fewer number of papers that used NPC's is also due to the fact mentioned above, in which, the creation requires a higher level of knowledge from the developer's.

Within this context, it is also included the use of Sloodle, that performs the integration of the virtual world (Second Life or OpenSim) with Moodle environment. Your goal is focused on facilitating the process of integration of educational materials in virtual worlds (slides, videos, images, among others), and to record the presence and performance of activities in the virtual world, such as questionnaires, directly into Moodle for further verification by the teacher. A total of nine papers used this tool in the research conducted, which had positive results to assist in the learning process.

Described the aspects related to the technological point of view, it is necessary to clarify the peculiarities relating to educational theories and lines of thought performed in these 58 papers. Analysis of selected research reflected the use of different foundations, including some that carried out the association of two or more theories in the same research, which follows the principles of: Collaborative Learning (6), Problem Based Learning (1), Experiential Learning (4), Meaningful Learning (2), Constructionism (4), Constructivism (1), Cognitive Load (1), Cognitive Flexibility (1), Planned Behavior (1) Flow Theory (2), Psychogenic Theory (1), Pedagogy of Genres (1), Teaching and Learning cycle (1) and Bloom's Taxonomy (2).

Some authors did not mention a specific theory that supported his research, on the other hand each of these investigations cited a recognized researcher, including: Vygotsky, Bloom, Piaget, Freire and Fletcher. In addition, other authors did not mention the educational theory or recognized researcher, which reach 34 papers.

In the case of the application areas of these 58 papers, were identified studies developed in the area of Computer Science (13), Physics (4), Foreign Language (4), Mathematics (3), Chemistry (2), Electronics (2), Science (2), Nursing (1), Archaeology (1), Literature (1), Business Administration (1) and Aerospace Engineering (1). Other items that did not have a specific area were classified as Authorship (8), Education Center and/or Administration (10) and Analysis of Students (5).

In order to represent information derived from the systematic review was chosen the graphical representation by a time series (Figure 2). Data obtained in the range of the years was analyzed, reproducing also, what were the employed educational theories and application areas in virtual worlds during this period. In view of this, was sought the discussion of the five most used theories in order to highlight their characteristics and present the virtual world elements that have been exploited for its implementation.

Studies that used educational theory with the objective of entails a collaborative learning, aimed to create opportunities for cooperation among students to perform any particular activity, a factor that is highlighted in the virtual worlds, because of the layout based on a shared space, in which, at the moment that a student make any changes, other colleagues can check in real time. Allied to this, students also have at their disposal the chat, which enables exchange of instant messages to the solution of questions and general discussion of a problem. 
V Congresso Brasileiro de Informática na Educação (CBIE 2016)

Anais do XXVII Simpósio Brasileiro de Informática na Educação (SBIE 2016)

This theory was applied in the fields of computing, mathematics, analysis of students and teaching centers and/or administration. These areas provide the opportunity for a learning based on collaboration, a factor that was featured through the experiments that aims greater exchange of knowledge and excelled by the use of a shared space.

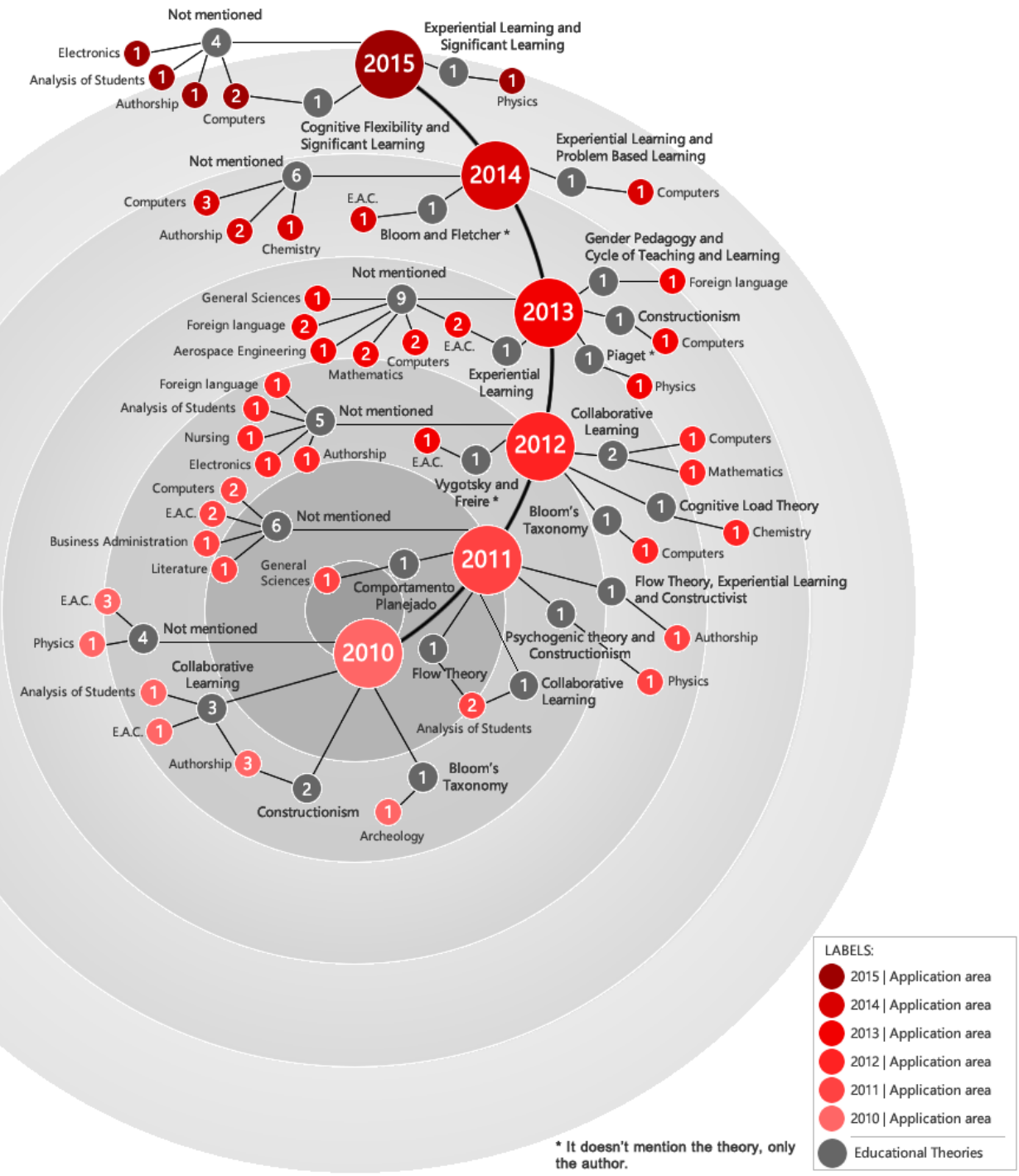

Figure 2. Temporal Analysis of Papers, Theory and Application Areas

Authors who conducted investigations based on Bloom's Taxonomy, that could be considered or not an educational theory, but is wide disseminated in an academic level and was chosen to be analyzed, sought to enable users of virtual worlds the three possibilities of learning that Bloom argues, through cognitive, affective and psychomotor. Areas of archeology and computing dealt with this theory, where contents for intellectual development were used, 3D objects and other elements available in the environment. This includes affective aspects of users, as well as performing the practical implementation of activities when immersed in the environment favoring the development of skills involving the motor apparatus of the student.

Studies developed based on experiential learning theory sought to allow the students to interact with a theory, and then provide them a practical experience. The 
V Congresso Brasileiro de Informática na Educação (CBIE 2016)

Anais do XXVII Simpósio Brasileiro de Informática na Educação (SBIE 2016)

common characteristic found in these papers, is that the authors aimed to create opportunities to students on the four stages of the cycle of Kolb, which defines: abstract design, concrete experience, reflection and observation. For then, at the end of the activities, students can test their hypothesis and eventually change their conceptions, remaking them mentally, affecting an active trial topic addressed in the environment. Associated with this theory, the authors used the flow theory, problem-based learning and meaningful learning, in order to create opportunities for learning in the areas of education and/or administration centers, authoring, physics and computing.

As for the virtual worlds implemented and based on constructionist theory, authors have worked on the development of activities that would promote the construction of knowledge based on the accomplishment of some concrete action, which could result in a tangible and of the interest of students immersed in the environment. This theory has been applied in the areas of authorship, computation and physics, which facilitates the performance of activities by the students immersed in the virtual world. Authors of these studies have encouraged students to interact with the objects available and even build their own 3D objects making modifications or additions, that would result in some action, which are performed by the use of programming scripts.

The authors who applied the theory of meaningful learning in the development of educational activities, focused at the use of the principles covered by Ausubel for the employment of subsumption concepts. Thus, promoting learning for the immersed users through existing content on the student cognitive structure was first offered a base, so that a more complex topic could be worked. From this perspective, it is possible to offer the student a growth by modifying the subsumption concept, causing an evolution of knowledge for the student. This theory was associated with the theory of experiential learning and cognitive flexibility, and worked in the areas of physics and computing.

Another important aspect to be considered is related to the way of the evolution of a student and the target audience. It was possible to determine in the 58 papers analyzed, that a total of 14 did not contain any evaluation with users, which only had the developed environment. This finding is due to the fact that in most of these papers was made a general presentation of the environment and the objectives aimed to achieve, usually associated with some educational theory which served as the basis for the construction of the environment, postponing for future work the application of assessments with users.

In other papers analyzed, it was possible to perform a division by four types of educational levels. The largest number of evaluations carried out involved undergraduate students (23) from different areas of education, since it is a stage, in which, it is possible to evaluate different subjects in a course of the same class for longer time. Unlike the post-graduate courses (7), which is a stage where students are more focused on their research and with fewer disciplines, which becomes more complicated to complete tests.

Courses with pre service teachers also had several studies carried out (8), in which were evaluated the developed environments for a particular subject area. Outnumbered are the studies in elementary school (6), as it comes to underage students that need permission of their parents in tests and may also be more difficult to understand the working environment and strictly follow a certain methodology applied. 
V Congresso Brasileiro de Informática na Educação (CBIE 2016)

Anais do XXVII Simpósio Brasileiro de Informática na Educação (SBIE 2016)

\section{Final Considerations}

Proliferation of studies of virtual worlds in the educational field corroborates in a motivational way to carry out this study, in which, through the systematic review method, it was performed the analysis of scientific productions referred to the theme and highlighted opportunities for future research. It becomes important to emphasize that the primary research carried out did not cover global search engines, that is, the search was focused on specific bases with papers of events and journals.

Thus, the methodology applied included the consistently review and analysis of all existing studies searched in the records of the main events and journals related to the topic investigated in this paper. Results can be considered instigators and clarifying, to the extent that it was possible to establish different interconnections and point out relations about the way that virtual worlds are being used within the educational context.

On thinking of the general point of view, this study allowed to demonstrate the diversity of areas, in which, virtual worlds has been used in accordance with the application of educational theories, in addition to several points of investigation that were clarified from the analysis of results. Within this context, it can be considered as a trend that will continue to progress over the next few years, based on the search for varied solutions in different educational areas by means of 3D simulations in this kind of environment, so that they can contribute to the process of teaching and learning.

\section{References}

Bell, M. W. (2008). Toward a definition of "virtual worlds". In Journal of Virtual Worlds Research, 1(1), p. 1-5.

Borges, S. D. S., Reis, H. M., Durelli, V. H. S., Bittencourt, I. I., Jaques, P. A. and Isotani, S. (2013). Gamificação Aplicada à Educação: Um Mapeamento Sistemático. In XXIV Simpósio Brasileiro de Informática Na Educação (SBIE), p. 234-243.

Ghanbarzadeh, R., Ghapanchi, A. H., Blumenstein, M. and Talaei-Khoei, A. (2014). A Decade of Research on the Use of Three-Dimensional Virtual Worlds in Health Care: A Systematic Literature Review. In Journal of Medical Internet Research, 16(2).

Kitchenham, B., Charters, S., Budgen, D., Brereton, P., Turner, M., Linkman,S., Jørgensen, M., Mendes, E. and Visaggio, G. (2007). Guidelines for performing Systematic Literature Reviews in Software Engineering. EBSE Technical Report, Keele University and University of Durham.

Krassmann, A. L., Paschoal, L. N., Falcade, A. and Medina, R. D. (2015). JASPION: Jogo Sério Educacional Sensível ao Contexto Integrado ao Mundo Virtual OpenSim. In XXVI Simpósio Brasileiro de Informática na Educação (SBIE), p. 429-438.

Nunes, E. P. d. S., Roque, L. G. and Nunes, F. d. L. d. S. (2016). Measuring Knowledge Acquisition in 3D Virtual Learning Environments. In IEEE Computer Graphics and Applications, vol. 36, no. 2, p. 58-67.

Oliveira, L. C. (2015). Artefato Metodológico de Autoria Aplicado aos Mundos Virtuais para Educação. Dissertação (Mestrado em Engenharia de Computação), Centro de Ciências Computacionais, Universidade Federal do Rio Grande, 181 p. 